\title{
A INSERÇÃO DOS CATADORES COMO EMPECILHO PARA AQUISIÇÃO DE METAS NO PLANO DE GESTÃO DOS RESÍDUOS SÓLIDOS MUNICIPAIS
}

\author{
Cisnara Pires Amaral ${ }^{1}$ \\ Diosnel Antonio Rodriguez Lopez²
}

Resumo: O trabalho consta de uma revisão bibliográfica realizada a partir da análise dos Planos de Gerenciamento de Resíduos Sólidos de cinco municípios situados na Região Centro-Oeste do Estado do Rio Grande do Sul, atendendo a Lei 12. 305/10 que incentiva a coleta seletiva, a integração dos catadores de materiais recicláveis em cooperativas e também a inserção desses munícipes na economia local. Conclui-se que um dos maiores empecilhos para a inclusão de metas favoráveis será a aceitação e organização dos munícipes que trabalham em condições insalubres, necessitando urgentemente de políticas públicas que priorizem e minimizem a exclusão.

Palavras-chave: Resíduos Sólidos; Gestão; Catadores.

${ }^{1}$ Universidade Regional Integrada do Alto Uruguai e das Missões. E-mail: cisnara@yahoo.com.br

2 Universidade de Santa Cruz do Sul. E-mail: diosnelrl@gmail.com 


\section{Introdução}

A sociedade contemporânea contribui essencialmente para o acúmulo de resíduos sólidos no ambiente, implicando na deterioração da qualidade de vida, afetando a saúde da população e contribuindo para a perda da biodiversidade. Toda essa degradação dos recursos naturais ocorre devido à ação antrópica. Dessa forma, observamos acúmulo de resíduos que auxiliam a proliferação de vetores, contaminando ar, água e solo.

Com o intuito de sanar o problema surge a Política Nacional de Resíduos Sólidos, aprovada por meio da Lei 12.305/10. Esta trouxe como prioridade o término dos lixões até 2014, tendo como objetivos implantar a coleta seletiva, a logística reversa e a compostagem dos resíduos. Essas demandas passaram a ser um desafio para a maioria das cidades, visto que as mudanças de valores e atitudes não são suficientes para gerar mudanças estruturais numa sociedade. As mudanças estruturais são necessárias, pois observamos frequente aumento na geração de resíduos.

Essa mesma Lei prevê a formação de planos municipais de gestão integrada de resíduos. Segundo o artigo $18^{\circ}$ da referida Lei, a elaboração desses planos dá condição para o Distrito Federal e os Municípios terem acesso a recursos da União, ou por ela controlados, como certos empreendimentos relacionados à limpeza urbana e ao manejo de resíduos sólidos, que poderão ser beneficiados por incentivos ou financiamentos de entidades federais de crédito ou fomento para tal finalidade.

O estabelecimento do PRGIRS- Plano Regional de Gestão Integrada dos Resíduos Sólidos, da Região Centro-Oeste envolve 27 municípios do RS. É uma associação de natureza autárquica que tem como objetivo estabelecer a gestão responsável e sustentável dos resíduos, tendo em vista subsidiar a gestão dos resíduos sólidos por meio de um conjunto de ações normativas, operacionais, financeiras e de planejamento.

Identificamos que até a intervenção da Lei $12.305 / 10$ a questão do tratamento adequado dos resíduos sólidos urbanos não era vista como prioridade pela gestão municipal, pois segundo IBGE 2010 ainda havia 2.906 lixões ativos no Brasil, distribuídos por 2.810 municípios. Em números absolutos, o Estado da Bahia teve a maioria dos municípios com lixões a céu aberto (360), seguido pelo Piauí (218), Minas Gerais (217) e Maranhão (207). Outras informações relevantes é que $98 \%$ dos lixões a céu aberto ficaram concentrados em cidades pequenas e $57 \%$ estavam no nordeste.

Observa-se então, que a organização em Planos Intermunicipais auxiliou a resolução dos problemas socioambientais pelos municípios pequenos e segundo PNRS, artigo 19, parágrafo 9:

Nos termos do regulamento, o município que optar por soluções consorciadas intermunicipais para a gestão de resíduos sólidos, assegurado que o plano intermunicipal preencha os requisitos previstos na Política Nacional de 
Resíduos Sólidos pode ser dispensado da elaboração do plano municipal de gestão integrada de resíduos sólidos.

Por meio da elaboração desses planos assegura-se o acesso a recursos federais de forma prioritária, conforme descrito na lei $12.305 / 10$ no artigo $18^{\circ}$, parágrafo $1 \stackrel{0}{0}$ :

I - Serão priorizados no acesso aos recursos da União os Municípios que optarem por soluções consorciadas intermunicipais para a gestão dos resíduos sólidos, incluída a elaboração e implementação de plano intermunicipal, ou que se inserirem de forma voluntária nos planos microrregionais de resíduos sólidos.

Segundo Barros (2012) numa situação de esgotamento e de comprometimento de recursos naturais, de problemas técnicos, financeiros, sociais e econômicos de disposição final de Resíduos Sólidos e com os impactos ambientais daí decorrentes, incluindo a contaminação, justifica-se cada vez mais o cuidado com uma gestão abrangente, integrada, recentemente dita sustentável; mais que a atenção com a etapa de sua evacuação, é necessário que sua produção seja diminuída e seus constituintes sejam revalorizados e reaproveitados.

Waldman (2003) observou que as causas da degradação ambiental são desencadeadas pelo capitalismo, argumentando que a expansão e a manutenção da demanda de produção são fatores que elevam o consumo, na média per capita, gerando uma enorme pressão na natureza. Tal, aliado ao livre mercado e à propriedade privada, incentiva à aquisição de cultura de exploração dos recursos naturais e humanos, instituindo a mercantilização da vida. Ainda, segundo o autor, a cultura de consumo se desenvolve numa movimentação de mercado que visa à geração de lucros crescentes, causando um aquecimento da economia que necessita constantemente de mais produção e mais consumo.

Dessa forma, observa-se que o consumo exagerado e desenfreado contribui para a proliferação de resíduos sólidos, e que os Planos de Gerenciamentos são meios para atingir metas favoráveis na gestão dos resíduos municipais, além de incentivar recursos financeiros provenientes da União, melhorando a qualidade de vida, incentivando o reaproveitamento.

\section{A influência dos catadores no contexto socioeconômico}

O modelo de consumo adotado pela sociedade contemporânea acarreta o esgotamento dos recursos naturais, o agravamento da pobreza e do desequilíbrio, pautado na acumulação e no desperdício. Surge daí a expressão "descartável", que passou a ser utilizada sem muito controle, desencadeando dois processos: de um lado, a quantidade e a qualidade dos resíduos gerados e, por outro lado, frente às políticas econômicas e sociais, uma massa de Revbea, São Paulo, V. 11, № 4: 78-89, 2016. 
excludentes, que passaram a se "beneficiar" dessa geração, que é a população de catadores de materiais recicláveis, entendida como meio de sobrevivência e obtenção de renda, ainda pouco estudados pela saúde pública ou qualquer outra área (WALDMAN, 2003).

A economia atual traz à tona uma realidade estabelecida em todos os segmentos da sociedade: os "catadores" que transitam pelas ruas das cidades recuperando lixo ou materiais que restam de qualquer atividade humana, normalmente na forma sólida, e que podem ser reaproveitados ou reciclados, trabalhando em sua maioria de maneira informal, sujeitos a vetores de doenças, degradando sua saúde.

A preocupação com a saúde é relevante visto que os catadores possuem rotina diária exaustiva, mostrando claramente as condições de vida em que estão inseridos. Magera (2003, p.34) afirma:

Muitas vezes, ultrapassam doze horas ininterruptas; um trabalho exaustivo, visto às condições a que estes indivíduos se submetem, com seus carrinhos puxados pela tração humana, carregando por dia mais de 200 quilos de lixo (cerca de 4 toneladas por mês), e percorrendo mais de vinte quilômetros por dia, sendo, no final, muitas vezes explorados pelos donos dos depósitos de lixo (sucateiros) que, num gesto de paternalismo, trocam os resíduos coletados do dia por bebida alcoólica ou pagam-Ihe um valor simbólico insuficiente para sua própria reprodução como catador de lixo.

Segundo Augusto et.al (2003), é com essa definição que o conceito de saúde se mostra como resultante das condições de vida e do ambiente. Ao mesmo tempo em que degradam o homem, sua qualidade de vida e seu estado de saúde, os padrões de desenvolvimento adotados vêm favorecendo a degradação ambiental por meio da exploração predatória dos recursos naturais, interferindo na vida social dos indivíduos.

Para Calderoni (2003) o mais comum é a criação de uma situação em que pessoas pobres convivem da pior maneira possível com resíduos que podem fornecer um precário sustento, mas que certamente trarão doenças, que agravarão as condições de vida da população e contribuirão para contaminar o ambiente.

Como o lixo é considerado um achado valioso pela população carente, os catadores constituem-se em uma comunidade de risco, não apenas para sua própria integridade física e de saúde, como também são submetidos a uma condição de marginalidade social e econômica, que muitas vezes se confunde com o próprio conceito de lixo.

Magera (2003), IPT (2003) e Miura (2004), relacionam o crescimento do número de catadores de materiais recicláveis com as crescentes exigências para o acesso ao mercado formal de trabalho e também ao aumento do 
desemprego. Para esses autores, alguns trabalhadores da catação constituem uma massa de desempregados que, por sua idade, condição social e baixa escolaridade, não encontram lugar no mercado formal de trabalho.

Guareshi (2004) afirma que o conceito de exclusão, no entendimento da sociedade contemporânea, é crucial porque as transformações do mundo do trabalho, principalmente, as advindas das transformações do modo de produção, modificam o cenário das relações sociais até então vigentes.

É imprescindível que ocorra a reestruturação das formas de organização desses munícipes. A reestruturação envolve a precariedade, o trabalho mal remunerado e pouco reconhecido, além de provocar no trabalhador um sentimento de menosprezo em relação a outros trabalhadores da sociedade. Outra dificuldade, ainda, surge na restrição dos direitos sociais, e na falta de perspectivas.

Paradoxalmente a essa situação foi criada a lei 12.305/10 que designa a prioridade para a gestão dos resíduos, incluindo a coleta seletiva, os sistemas de logística reversa, o incentivo a criação e ao desenvolvimento de cooperativas e outras formas de associação dos catadores de materiais recicláveis. Um dos aspectos apresentados na Lei é o apoio à inclusão produtiva dos catadores de materiais reutilizáveis ou recicláveis, priorizando a participação em cooperativas ou outras formas de associação.

\section{Desafios éticos da sociedade em relação ao grupo de catadores}

Observa-se que para resolver os problemas socioambientais é necessário preparar o ser humano para compreender e reconhecer a profunda interdependência entre os sistemas, conscientizando para a continuidade dos vínculos existentes entre nossas ações presentes com consequências futuras.

Os costumes, estilos de vida, a realidade cultural e política, a visão dos valores éticos e religiosos, estão se transformando rapidamente. Há uma crise ética em curso e ela mexe com a identidade tanto de pessoas adultas quanto de instituições tidas durante séculos como definitivas.

Acabamos nos acostumando com a degradação ambiental, exploração dos recursos naturais e "exclusão social". Desse modo, vivenciamos a época do individualismo, do egoísmo, da busca pelo novo. Afirma Libâneo (2001) na vida cotidiana, é cada vez maior o número de pessoas atingidas pelas novas tecnologias, pelos novos hábitos e indução de novas necessidades.

Segundo Barbosa et al. (2012) sempre estamos aprendendo de que maneira devemos atuar, sentir ou pensar, em distintas situações. Isto é: somos socializados durante toda a nossa vida. Assim, podemos compartilhar, com os demais membros de nossas sociedades, valores morais ou estéticos, gostos, linguagens e sentimentos, e acompanhar as mudanças pelas quais eles vão passando.

Esse mesmo autor também observa que é importante distinguir a percepção do cidadão comum sobre o mundo, ou o senso comum, da Revbea, São Paulo, V. 11, No 4: 78-89, 2016. 
perspectiva científica, o conhecimento desenvolve um olhar que permite ir além das observações impressionistas para estabelecer quais são os princípios e as regras sociais que organizam um determinado fato.

Relata Lipovetzky (1993 apud SILVA, 2015, p.4)

vivemos tempos em que não existem ordens opostas nem bem definidas; tudo é aceito, em uma atitude de total liberalismo e subjetivismo. Assim, o individual predomina sobre o universal, o psicológico sobre o ideológico, a comunicação sobre a politização, à diversidade sobre a homogeneidade, o permissivo sobre o coercitivo.

Bauman (1998 apud SILVA, 2015, p.4) relata que vivenciamos a era da liquidez, sendo que os valores que a nossa cultura ocidental até, então, estabelecera como os mais nobres e elevados, cada vez mais se diluem como a água que escorre das nossas mãos, sem que sejamos capazes de detê-la. Ou seja, uma sociedade de relações fluidas, frágeis.

São as relações frágeis formadas em sociedade, responsáveis pela exclusão social, relacionando a situação de desemprego com o sinônimo de marginalidade. Ao mesmo tempo, conseguimos levar em conta que os catadores trabalham exaustivamente de forma informal, auxiliando a modificação do cenário caótico referente aos resíduos sólidos urbanos.

Para Miura (2004), o problema hoje não está em reconhecer legalmente o catador como um profissional, mas, sim, em reconhecer seu direito às condições dignas de trabalho e de vida, para além da perspectiva estrita da sobrevivência.

Enfatiza Migueles (2004), "para que a sociedade perceba o catador como 'um outro trabalhador qualquer' é preciso associar o trabalho de catação a significados positivos"

Assim sendo, o modelo socioeconômico atual induz ao desemprego, a falta de oportunidades no mercado de trabalho, aliada a condição econômica e analfabetismo, fatores geradores de condições propícias, para que os menos favorecidos trabalhem na reciclagem, promovendo seu sustento e de sua família.

\section{Metodologia}

Para a realização desse trabalho foi utilizado como base o Plano de Gerenciamento de Resíduos Sólidos dos municípios de Santiago, Jaguari, São Francisco de Assis, Unistalda e Nova Esperança do Sul. Todos os municípios localizados na Região Centro-oeste do RS. Destes, Santiago possui Plano de Gerenciamento de Resíduos próprio e os demais estão inseridos no Consórcio Intermunicipal da Região Centro-oeste, conforme previsto na Lei 12.305/10. 
Por meio desses materiais conseguimos realizar um diagnóstico social da situação dos catadores nos municípios que possuem população estimada pelo IBGE em 2010 de 49.071 habitantes em Santiago, 11.396 habitantes em Jaguari, 4.722 habitantes em Nova Esperança do Sul, 19.135 habitantes em São Francisco de Assis e 2.436 habitantes em Unistalda.

Segundo Gil (2008), a pesquisa bibliográfica é desenvolvida com base em material já elaborado, constituído principalmente de livros e artigos científicos.

O trabalho consta de uma análise dos dados apresentados no Plano de Gerenciamento dos Resíduos Sólidos dos municípios em comparação com o que está estabelecido na legislação, observando a contribuição da atividade realizada pelos catadores, o envolvimento desses catadores em associações, a dificuldade de estratégias e metas para conseguir integrar esse grupo ao sistema de gerenciamento de Resíduos Sólidos.

\section{Análise e Discussão}

Através da análise dos dados, constatou-se que todos os municípios possuem planos que contemplam as metas estabelecidas pela Lei 12.305/10, porém identificamos que um dos maiores empecilhos é a falta da valorização e organização dos catadores em cooperativas. O grande entrave é a dificuldade de auxílio, de superação, para que esses munícipes encontrem valorização profissional, sintam-se incluídos no contexto socioeconômico, e que a atividade de "catação" seja vista como uma atividade formal.

Velloso (2005) afirma que o desenvolvimento do potencial de criação do sujeito está relacionado a um ambiente propício, ou seja, um ambiente onde ele possa ter espaço para desenvolver sua singularidade e reintegrá-lo à realidade externa pelas atitudes culturais, sociais e políticas, ou seja, a inserção do sujeito na sociedade deve se dar por meio de sua interação dinâmica com o mundo externo.

Além disso, encontramos atrelado à toda essa situação os atravessadores, que contribuem dificultando para que ocorra a organização em cooperativas, pois entram em contato com o responsável pela reciclagem, diminuindo o lucro, ofertando o que acham viável pelo material triado.

Viana (2000) observa que a existência dos atravessadores pode ser explicada por dois fatores principais: primeiro, pela dificuldade de locomoção dos catadores de lixo para entregar o material nas indústrias de reciclagem e, segundo, pelas vantagens que esse sistema oferece as indústrias.

Carmo (2005) afirma que os catadores desconhecem completamente os aspectos que envolvem a logística do processo da reciclagem, assim, cria-se uma barreira gerada pelo desconhecimento atribuído à baixa escolaridade, um dos grandes empecilhos para obterem melhores lucros.

Observamos que a gestão dos municípios deveria criar planos, estratégias ou metas para a organização em cooperativas, esclarecendo aos 
munícipes envolvidos na reciclagem sobre os benefícios a que estarão sujeitos acaso optem por esse tipo de associação. IPT (2003) destaca que as vantagens da cooperativa são para evitar a dependência de um único comprador, também vender cargas "fechadas" por um preço médio ou estocar materiais. Estes poderão ser armazenados por períodos mais longos, se o galpão de triagem dispuser de espaço e houver capital de giro.

Ainda conforme o IPT (2003), o objetivo central de uma cooperativa de catadores de material reciclável é gerar oportunidades de trabalho e renda. Das vantagens econômicas advindas da organização em cooperativas de trabalho, o IPT apresenta o fato de os catadores conseguirem um valor mais alto pelo produto, pois ofertam produtos com melhores condições de limpeza e classificação e barateiam o transporte, prensando as cargas.

Constatamos que o número de catadores informais relacionados nos Planos de Gestão é maior que o número de catadores associados em cooperativas, sendo que Santiago consta com 2 cooperativas, ARPES (Associação dos Profetas Recicladores de Santiago) com 15 associados e a COMARES (Cooperativa de Materiais Recicláveis) com 25 associados e 40 recicladores autônomos registrados pela prefeitura. No município de Jaguari, temos somente 1 cooperativa, com 8 associados e 12 catadores informais; em São Francisco de Assis não existe cooperativa, somente catadores informais, em número de 20. Nova Esperança do Sul consta com uma cooperativa com 5 catadores e não existem informações sobre catadores autônomos. Já em Unistalda foram registrados 2 catadores autônomos, porém não existem cooperativas.

Refletindo sobre o assunto acabamos nos perguntando se todos esses munícipes têm informações sobre a significância de uma cooperativa, de como organizar essa associação ou ajuda dos municípios em se articular? Marinho (2005) afirma que para abordar as transformações no denominado "mundo do trabalho" tem-se que considerar o processo de reestruturação produtiva, pois "as relações de trabalho e as formas de organização dos trabalhadores estão profundamente relacionadas com as transformações da produção e do mercado".

Entendemos que a atividade dos catadores informais acaba por onerar as prefeituras, pois deverão deslocar equipes de limpeza para as vias públicas; além de estarem expostos a vetores de doenças como moscas, baratas e outros patógenos.

A pesquisa demonstrou que as prefeituras não possuem quantificação de dados sobre os resíduos recolhidos pelo grupo de catadores informais, o que dificulta a associação dessa prática com os benefícios econômicos.

Compreendemos a relevância desse tema, que deverá buscar soluções para resolver os problemas dos resíduos sólidos urbanos, desde a sua produção até seu destino final. A problemática dos resíduos envolve todos os segmentos da sociedade, deve também partir de cada indivíduo, ou seja, o singular deverá interagir com a coletividade, devendo ocorrer o entendimento 
de que a reciclagem é uma ferramenta para o reaproveitamento de materiais descartados, trazendo benefícios ambientais, por meio da economia da utilização dos recursos naturais, lembrando ainda que esta ação beneficiará as indústrias com matérias-primas.

\section{Conclusão}

Observamos no decorrer da análise do material bibliográfico que a atividade de "catação" foi descrita pela primeira vez em 1980 quando ocorreu a formação das primeiras cooperativas com o intuito de valorização profissional, ocorrendo em 2001 o " $1^{\circ}$ Congresso Nacional de Catadores de Materiais Recicláveis e a $1^{\text {a }}$ Marcha da População de Rua" (MAGERA, 2003, p.105) desde então, essas relações de trabalho aumentaram significativamente, porém não ocorreu o envolvimento e a preocupação das gestões públicas em melhorar a qualidade de vida e a organização dos catadores.

Dessa forma, a simples elaboração do Plano de Resíduos e a não implementação de um dos seus objetivos dificulta a necessidade de reconhecer a importância dos recicladores no contexto socioeconômico do município. Além do mais são sujeitos que possuem uma rotina de trabalho exaustiva, e não especifica meios para inseri-los, nem os valorizar dentro do contexto de gestão de Resíduos Sólidos, embora a lei preconize a importância do estabelecimento de metas para a inclusão dos catadores.

Observamos que em todos os municípios estudados o número de catadores informais excede o número de catadores organizados em cooperativas, deixando claro que é necessário o desenvolvimento de estratégias para articular serviços de apoio a esses trabalhadores.

Por fim, notou-se que a exclusão continuará afetando as relações sociais desses indivíduos por meio da perda da identidade social, dificultando a percepção pela sociedade da importância dos recicladores. À falta de normatização das relações de reciclagem podem levar a acúmulos de resíduos em frente as suas casas, contribuindo para proliferação de insetos e doenças. Estando sem legalização, não podem reivindicar preços melhores, submetendo-se a desonestidade.

Essa forma de gestão pública continuará projetando à visão preconceituosa, além de dificultar a percepção da função social desses sujeitos que trabalham na reciclagem, auxiliam e evitam o acúmulo de produtos indesejados, podendo ser reaproveitados. É fundamental que a sociedade entenda a importância desses sujeitos na manutenção do meio, então, quando não organizados em cooperativas são vistos como fator de marginalidade.

A organização em cooperativas poderá tornar o trabalho menos exaustivo, contribuirá para a inclusão social, possibilitará a competitividade através do aumento da oferta de materiais recicláveis. Também são necessárias ações sociais para que o catador reconheça a importância de sua contribuição na manutenção da organização municipal, melhorando sua autoestima. As ações 
sociais devem ser estendidas a toda a população para que ocorra valorização do outro, reconhecendo a atividade insalubre, entretanto de total importância para a economia.

Portanto, o empecilho está em estabelecer uma conexão entre a dialética inclusão/ exclusão, entendendo que mediante o processo da catação temos um grupo de indivíduos que mantém sua sobrevivência e de sua família, executando um trabalho desprovido de garantias trabalhistas, totalmente informais e que a exclusão continuará acontecendo a menos que as metas sejam prioridades para as gestões municipais.

\section{Agradecimentos}

Às Prefeituras Municipais dos municípios de Santiago, Jaguari, São Francisco de Assis, Unistalda e Nova Esperança do Sul pelo apoio e colaboração a pesquisa.

\section{Referências}

ABRELPE - Associação Brasileira das Empresas de limpeza Pública e Resíduos Especiais. Panorama dos Resíduos Sólidos no Brasil 2013. Disponível em http://www.abrelpe.org.br/Panorama/panorama2009.pdf. Acesso em maio de 2015.

ASSOCIAÇÃO BRASILEIRA DE NORMAS TÉCNICAS, 2004. Resíduos Sólidos - classificação. NBR 10.004. ABNT, Rio de Janeiro.

AUGUSTO, L.G.S.; CÂMARA, V.M.; CARNEIRO, F.F.; CÂNCIO, N. Saúde e Ambiente: uma reflexão da Associação Brasileira de Pós-Graduação em Saúde Coletiva (ABRASCO). Rev. Bras. Epidemiologia. 2003; 6 (2): 87-94.

BARBOSA, M.L.O.; QUINTANEIRO, T.; RIVERO, P. Conhecimento e Imaginação: Sociologia para o Ensino Médio. Belo Horizonte: Autêntica Editora, 2012.

BARROS, R.T.V. Elementos de Gestão de Resíduos Sólidos. Belo Horizonte: Tessitura, 2012.

BRASIL, Ministério do Meio Ambiente. 2012. Planos de Gestão de resíduos Sólidos: Manual de orientação. Brasília, DF.

BRASIL. 2010. Política Nacional de Resíduos Sólidos. Lei 12.305, de 02 de agosto de 2010. Institui a Política Nacional de Resíduos Sólidos; altera a Lei 9.605, de 12 de fevereiro de 1998, e dá outras providências. DOU, S.1 - Atos Poder legislativo, Ed 147 de 3/08/2010.

CALDERONI, S. Os bilhões perdidos no lixo. $4^{\mathrm{a}}$ ed. São Paulo: Humanitás Editora/ FFLCH/ USP, 2003.

CAPUCHA, L. Desafios da Pobreza, Oeiras, Celta Editora, 2005. 
CARMO, M.S. A semântica "negativa" do lixo como fator "positivo" à sobrevivência da Catação - Estudo de caso sobre a associação dos recicladores do Rio de Janeiro. Anais do Encontro Nacional da Associação Nacional de Pós-Graduação em Pesquisa em Administração - ENANPAD, Brasília - DF (2005).

FERREIRA, S.L. Os catadores do lixo na construção de uma nova cultura: a de separar o lixo e da consciência ambiental. Rer Urutágua - Revista Acadêmica Multidisciplinar .Quadrimestral no7, dez. 2004.[acessado 2015 mar 03];

GIL, A.C. Como elaborar projetos de pesquisa. 4. ed. São Paulo: Atlas, 2008.

GUARESHI, P. A. Psicologia social crítica como prática de libertação. Porto Alegre: EDIPUCRS, 2004.

INSTITUTO BRASILEIRO DE GEOGRAFIA E ESTATÍSTICA (IBGE) Brasil: 2010.

Instituto de Pesquisa Tecnológica - IPT. Cooperativa de catadores de materiais recicláveis: guia para implantação. São Paulo: SEBRAE,(2003).

LIBÂNEO, J.L. Adeus professor, adeus professora? Novas exigências educacionais e profissão docente. 5aㅡ ed. São Paulo: Cortez Editora, 2001.

LEAL, A.C.; JÚNIOR, A.T.; et al. A reinserção do lixo na sociedade do capital: uma contribuição ao entendimento do trabalho na catação e na reciclagem. Revista Terra Livre, São Paulo, 18 (19), 177-190, jul/dez (2002).

MAGERA, M. Os empresários do Lixo: um paradoxo da modernidade. Campinas, São Paulo: Átomo,2003.

MARINHO,M.C.N. As transformações no mundo do trabalho e suas implicações na formação do executivo. Universidade católica de Goiás. (Dissertação de Mestrado em Psicologia). Goiânia, GO, 2005.

MIGUELES, C. P. Significado do lixo e ação econômica - a semântica do lixo e o trabalho dos catadores do Rio de Janeiro. Anais do Encontro Nacional da Associação Nacional de Pós-Graduação em Pesquisa em Administração - ENANPAD, Curitiba - PR, 2004.

MIURA, P.C.O. Tornar-se catador: uma análise psicossocial. (Dissertação de Mestrado em Psicologia Social). Pontíficia Universidade Católica de São Paulo, SP, 2004.

PORTO, M.F.S.; JUNCÁ, D.C.M. et al.; Lixo, trabalho e saúde: um estudo de caso com catadores em um aterro metropolitano no Rio de Janeiro, Brasil. Cad. Saúde Pública 2004; 20(6): 1503-1514.

SANTIAGO, Prefeitura Municipal de Santiago. Plano de Gerenciamento Integrado de Resíduos Sólidos - PGIRS, 2013. 
SILVA, J.C.; COSTA, A.A.D.; ZARO, J. Educação Humanizadora e os desafios éticos na sociedade pós-moderna. VI Congresso Internacional de Educação: Editora Biblos. Santa Maria. 2015.

VELLOSO, M.P. Os catadores de lixo e o processo de emancipação social. Revista Ciência e Saúde Coletiva, Rio de Janeiro, 2005.

VIANA, N. Catadores de lixo: renda familiar, consumo e trabalho precoce. Revista Estudos da Universidade Católica de Goiás. 2000, 27(3), 407-691 WALDMAN, M. História da cidadania. São Paulo: Contexto; 2003. 